PREPARED FOR THE U.S. DEPARTMENT OF ENERGY, UNDER CONTRACT DE-AC02-76CH03073

PPPL-3974

PPPL-3974

UC-70

\title{
Measurement of Tritium Surface Distribution on TFTR Bumper Limiter Tiles
}

by

K. Sugiyama, T. Tanabe,

C.H. Skinner, and C.A. Gentile

June 2004

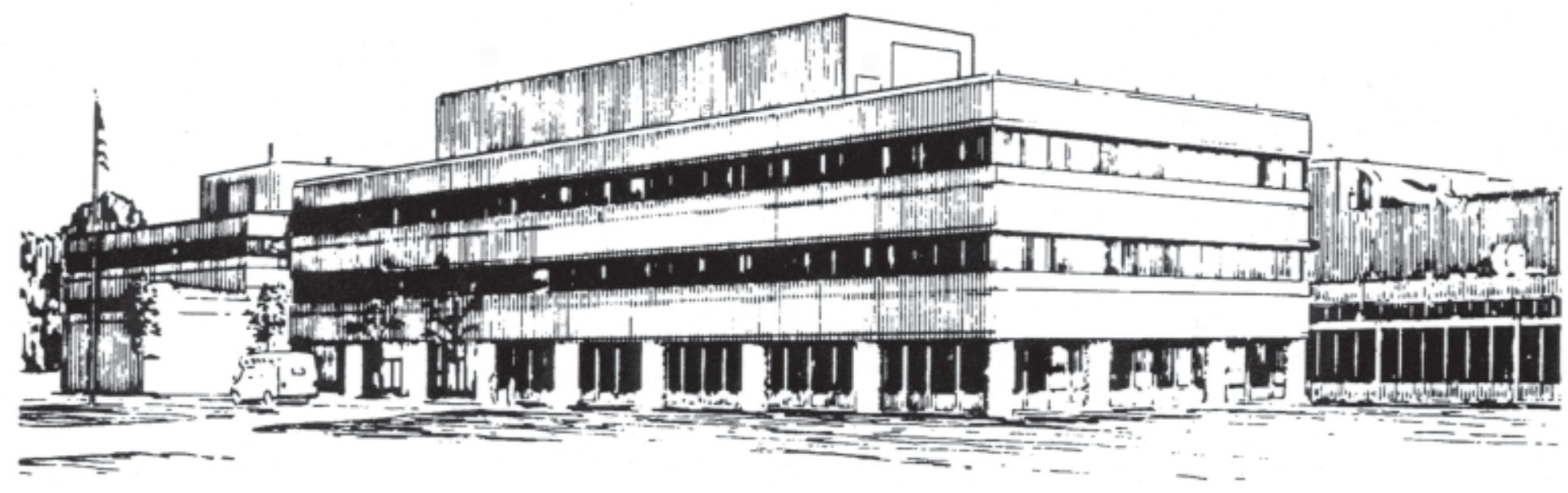

PRINCETON PLASMA PHYSICS LABORATORY PRINCETON UNIVERSITY, PRINCETON, NEW JERSEY 


\section{PPPL Reports Disclaimer}

This report was prepared as an account of work sponsored by an agency of the United States Government. Neither the United States Government nor any agency thereof, nor any of their employees, makes any warranty, express or implied, or assumes any legal liability or responsibility for the accuracy, completeness, or usefulness of any information, apparatus, product, or process disclosed, or represents that its use would not infringe privately owned rights. Reference herein to any specific commercial product, process, or service by trade name, trademark, manufacturer, or otherwise, does not necessarily constitute or imply its endorsement, recommendation, or favoring by the United States Government or any agency thereof. The views and opinions of authors expressed herein do not necessarily state or reflect those of the United States Government or any agency thereof.

\section{Availability}

This report is posted on the U.S. Department of Energy's Princeton Plasma Physics Laboratory Publications and Reports web site in Fiscal Year 2004. The home page for PPPL Reports and Publications is: http://www.pppl.gov/pub_report/

DOE and DOE Contractors can obtain copies of this report from:

U.S. Department of Energy

Office of Scientific and Technical Information

DOE Technical Information Services (DTIS)

P.O. Box 62

Oak Ridge, TN 37831

Telephone: (865) 576-8401

Fax: (865) 576-5728

Email: reports@adonis.osti.gov

This report is available to the general public from:

National Technical Information Service

U.S. Department of Commerce

5285 Port Royal Road

Springfield, VA 22161

Telephone: $1-800-553-6847$ or

(703) $605-6000$

Fax: (703) 321-8547

Internet: http://www.ntis.gov/ordering.htm 


\title{
Measurement of Tritium Surface Distribution on TFTR Bumper Limiter Tiles
}

\author{
K. Sugiyama ${ }^{1, *}$, T. Tanabe ${ }^{1}$, C. H. Skinner ${ }^{2}$ and C. A. Gentile ${ }^{2}$ \\ ${ }^{1}$ Department of Nuclear Engineering, Graduate School of Engineering, Nagoya University, Furo-cho, Chikusa-ku, Nagoya 464-8603, Japan \\ ${ }^{2}$ Princeton Plasma Physics Laboratory, Princeton NJ 08543, USA
}

Received June 26, 2003; accepted August 28, 2003

PACS Ref: $52.40 . \mathrm{Hf}$

\begin{abstract}
The tritium surface distribution on graphite tiles used in the TFTR bumper limiter and exposed to TFTR D-T discharges from 1993 to 1997 was measured by the Tritium Imaging Plate Technique (TIPT). The TFTR bumper limiter shows both re-/co-deposition and erosion. The tritium images for all tiles measured are strongly correlated with erosion and deposition patterns, and long-term tritium retention was found in the re-/co-depositions and flakes.

The CFC tiles located at erosion dominated areas clearly showed their woven structure in their tritium images owing to different erosion yields between fibers and matrix. Significantly high tritium retention was observed on all sides of the erosion tiles, indicating carbon transport via repetition of local erosion/deposition cycles.
\end{abstract}

\section{Introduction}

Tritium retention is a critical problem for next-step fusion reactors with carbon plasma facing components. Significant amounts of tritium are retained by codeposition with eroded wall materials. In D-T machines such as the Joint European Torus (JET), for example, the initial tritium retention fraction reached around $40 \%$ of the input during the DTE1 campaign [1]. Determining where and how tritium is retained is important for not only for safety issues, but also for clarifying the transport of erosion products and the development of tritium removal methods.

The Tokamak Fusion Test Reactor (TFTR) operated with D-T discharges from 1993 to 1997 until TFTR was shut down. During this period, 5.2 $\mathrm{g}(1.86 \mathrm{PBq})$ of tritium was introduced into the vacuum vessel through neutral beam injection and gas puffs. It was estimated that approximately $16 \%$ of introduced tritium still remained in the vessel after several tritium removal operations carried out after termination of the D-T campaign [2]. Since TFTR employed D-T plasmas and its bumper limiter was composed of graphite and Carbon-Fiber-Composite (CFC) tiles, the tritium distribution on the bumper limiter gives significant information of plasma-limiter interaction [3] as well as hydrogen retention properties.

The Imaging Plate (IP), radiation detector has been successfully used to obtain the 2-D tritium distribution on plasma-facing components of several fusion experimental devices [4-7]. In this study, the tritium surface distribution on the TFTR bumper limiter tiles was measured by IPs. Details of the IP measurement technique have been given elsewhere [4-7].

\footnotetext{
*e-mail: h022413m@mbox.nagoya-u.ac.jp
}

\section{Experimental}

The TFTR bumper limiter was mounted on the inner wall and was divided into 20 sectors labeled from bay-A to -T. The total area was $22 \mathrm{~m}^{2}$ of which approximately $30 \%$ contacted the plasma. On the limiter, some synergistic phenomena, such as erosion and co/redeposition, were caused by plasma-limiter interaction. High heat flux areas were covered with 4-D coarse weave Carbon-FiberComposite (CFC) made by Fiber Material Inc. and 3-D fine weave CFC tiles by Hercules, and the remainder were AXF-5Q isotopic graphite by Union Carbide. Figure 1 shows one sector (bay-K) of the bumper limiter. The tile KA7 (graphite) used in this study was taken from the deposition-dominated area, $\mathrm{KC10}$ (CFC) from erosion and deposition area, and $\mathrm{KC} 3$ (CFC) and KC4 (graphite) from erosion dominated area.

The IP used in this work was BAS-2025 and -2040 with high sensitivity for low-energy radiation such as $\beta$-ray from tritium decay. Since dust and flakes from codeposits were highly mobile [8], tiles were handled inside a fume hood to avoid tritium contamination, and the IP was wrapped by two layers of $2 \mu \mathrm{m}$ (micron) thickness Poly-PhenyleneSulfide (PPS) film. (One layer was insufficient to meet the stringent PPPL free release requirement of $1000 \mathrm{dpm} / 100 \mathrm{~cm}^{2}$ ). Since these two thin films are apt to stick to each other because of static electricity, a sheet of paper was inserted between them on the back of the IP to facilitate the separate removal of each film. Then, the surface of the wrapped IP was placed in contact with the surface of a tile for about $1 \mathrm{~h}$ in a dark room. Since the tile surface was slightly curved, a plastic bag with about $200 \mathrm{~g}$ of sand was placed on top of the IP to ensure close contact to the tile surface. After the exposure, the outer film was removed inside the fume hood and the IP transferred to an area outside the fume hood where the inner film was removed. The internal side of the inner film (directly faced to the IP surface) was smeared for contamination check. With these precautions the IPs had contamination levels of $100 \mathrm{dpm} / 100 \mathrm{~cm}^{2}$ or less, and could be freely released. The IPs were read out the day following the exposure by an imaging plate reader, Fuji BAS-2500 (also manufactured by Fuji Photo Co. Ltd.) located at Brookhaven National Laboratory (BNL). The resulting PSL (Photo-StimulatedLuminescence) intensity corresponds to the relative radioactivity, and is proportional to the dose absorbed in the IP. In this way the surface profile of retained tritium (tritium image) and other radioactive nuclides is obtained from the PSL intensity profile. 


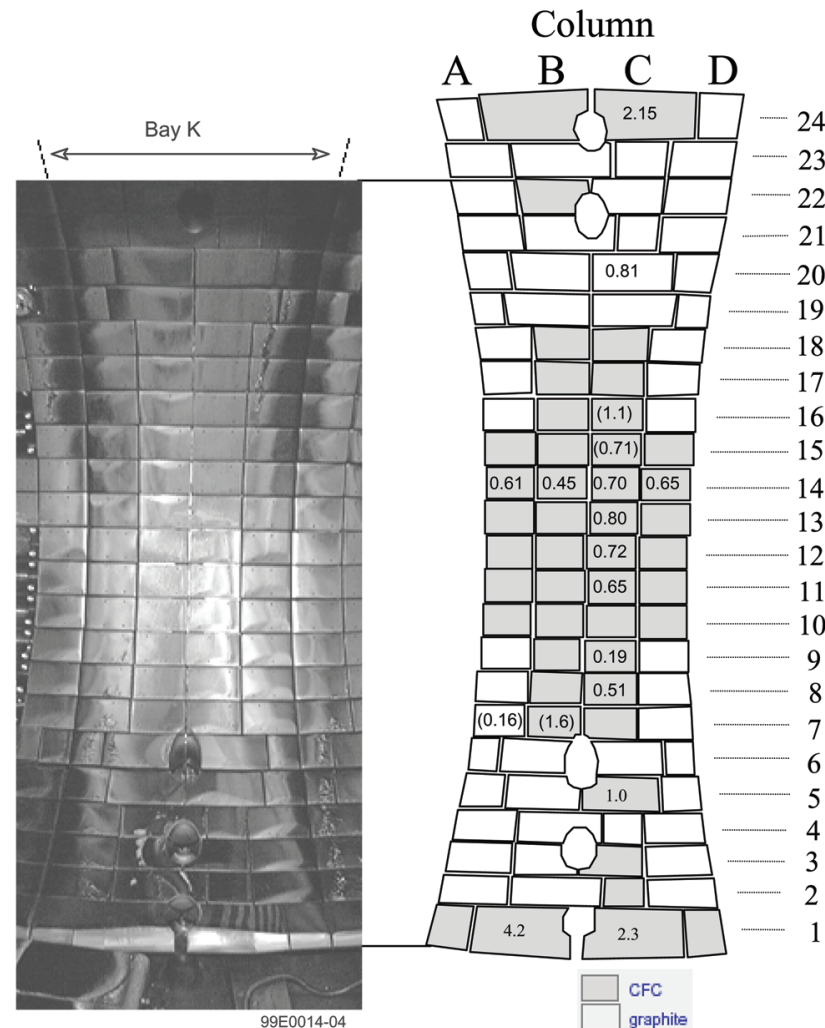

Fig. 1. Segment of the TFTR bumper limiter. Each tile was named in accordance with its position. (In case of $\mathrm{KC10}$, " $\mathrm{K}$ " is derived from bay" $\mathrm{K}$ ", " $\mathrm{C}$ " is from column-" $\mathrm{C}$ " and " 10 " is from row-" 10 ".) The number represents tritium released by bake out $\left(500^{\circ} \mathrm{C}, 1 \mathrm{~h}\right)$. The numbers in parentheses are results from tiles in the adjoining Bay $\mathrm{L}$.

Taking into account the attenuation of the $4 \mu \mathrm{m}$ $\left(\sim 0.5 \mathrm{mg} / \mathrm{cm}^{2}\right)$ film and the range of $\beta$-electrons from tritium, the IP image reflects mainly the tritium retained from the top surface to about $0.2 \mu \mathrm{m}$ depth. In some cases, additional experiments using $12 \mu \mathrm{m}$ thickness film were also carried out in order to distinguish the contribution of other radioactive sources such as activated metals.

\section{Results}

Figure 2. shows the results for graphite tile KA7 which was installed in the deposition dominated area located at about 30 degrees in poloidal angle below the middle-plane of the bumper limiter. As seen in the photograph taken when the tile was in the vessel (Fig. 2(a)), the tile was covered with deposition layers with fragile flakes of $10-50 \mu \mathrm{m}$ thickness [9]. After removing the tile from the vacuum vessel, some of the flakes became detached as seen in Fig. 2(b). The tritium image is quite similar to the photograph and tritium retention is quite low at the place where the flakes peeled off. On the other hand, the tritium retention was very large in the flakes and the redeposited layers. This indicates that the co/redeposition is the major retainer of tritium in the D-T reactor as pointed out in various previous studies. This result means that the tritium image corresponds well to erosion-deposition patterns.

Figure 3 compares photographs of $\mathrm{KC} 10$ made of 3-D CFC and located at erosion and deposition area and its tritium image. In the eroded area, one can see the $3-\mathrm{D}$
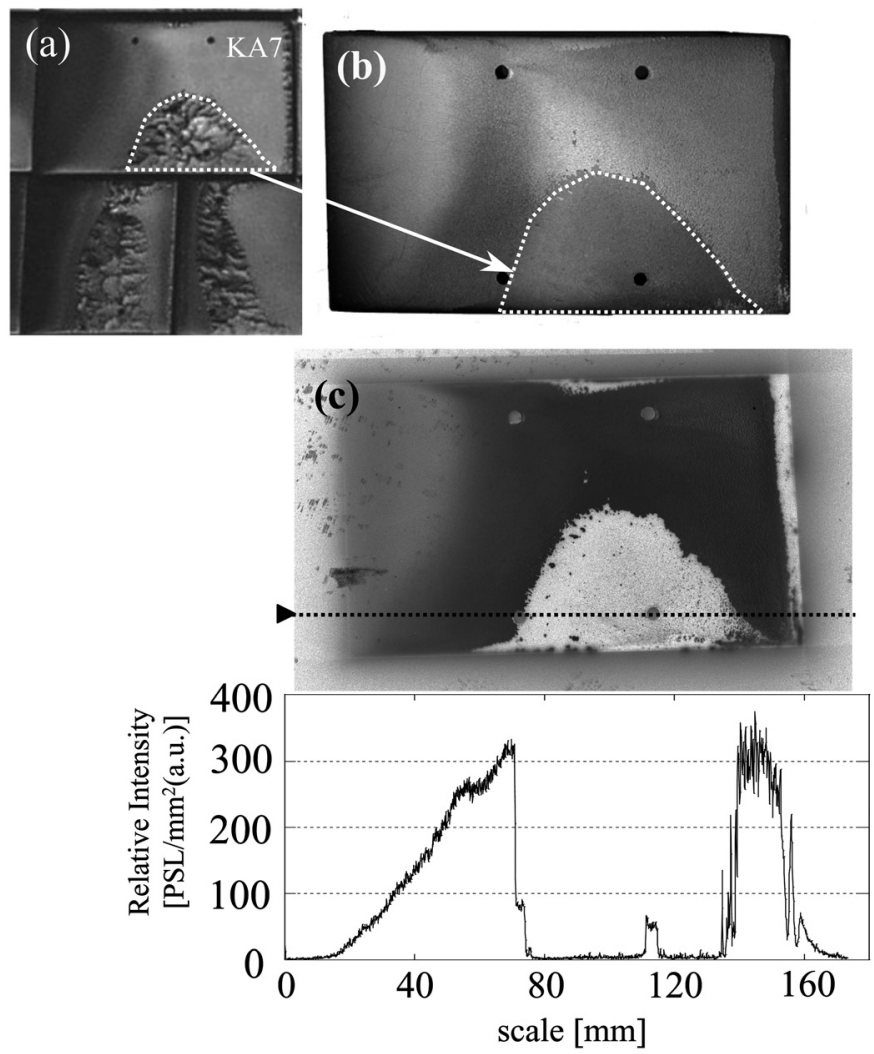

Fig. 2. Tile KA7 located at middle region of the Bumper Limiter. (a) Photograph of the tile taken before removing the tile from the vessel. Ultra fragile thin flakes are visible on the tile surface. (b) Photograph and (c) tritium image (in gray scale) of KA7 taken after removal from the vessel.

woven structure more clearly in the tritium image than in the photograph. In addition, the tritium image of tile $\mathrm{KC} 10$ shows a very clear contrast between eroded and deposited areas (Fig. 3).

The different erosion behavior, or different tritium deposition profiles, between two neighboring tiles, i.e., $\mathrm{CFC}(\mathrm{KC} 3)$ and graphite $(\mathrm{KC} 4)$ tiles, is compared in Fig. 4. The two neighboring tiles were near the bottom surrounding a diagnostic port and were heavily eroded due to the high particle flux [10].

The tritium image of the $\mathrm{CFC}$ (KC3) tile shows very clearly the woven structure again, while the graphite (KC4) tile shows very homogeneous tritium retention. In the magnified tritium image (Fig. 5) of the CFC tile, one can see a very interesting tritium retention profile, i.e., not only the pattern of woven carbon fibers is clearly visible in this IP image, but also the difference of tritium retention between matrix and fibers. Comparatively high tritium concentration is found in the matrix area in between the fibers bundles.

It is also noted that all tile sides showed high levels of tritium retention (see Fig. 4(b) and (d)). Previous analyses of the tile used in the TFTR D-D phase showed deuterium deposition on the side surface of the limiter tiles [11-13]. In the present measurement, tiles from the erosion-dominant regions (such as $\mathrm{KC} 2,3$ and 4) had much higher PSL intensities on their side surfaces.

It should be mentioned that the radioactive metallic impurities ${ }^{57} \mathrm{Co},{ }^{60} \mathrm{Co}$ were also detected on the tile surface by a gamma spectrometer. (Earlier studies have shown a similar deposition pattern of deuterium and metals on the 


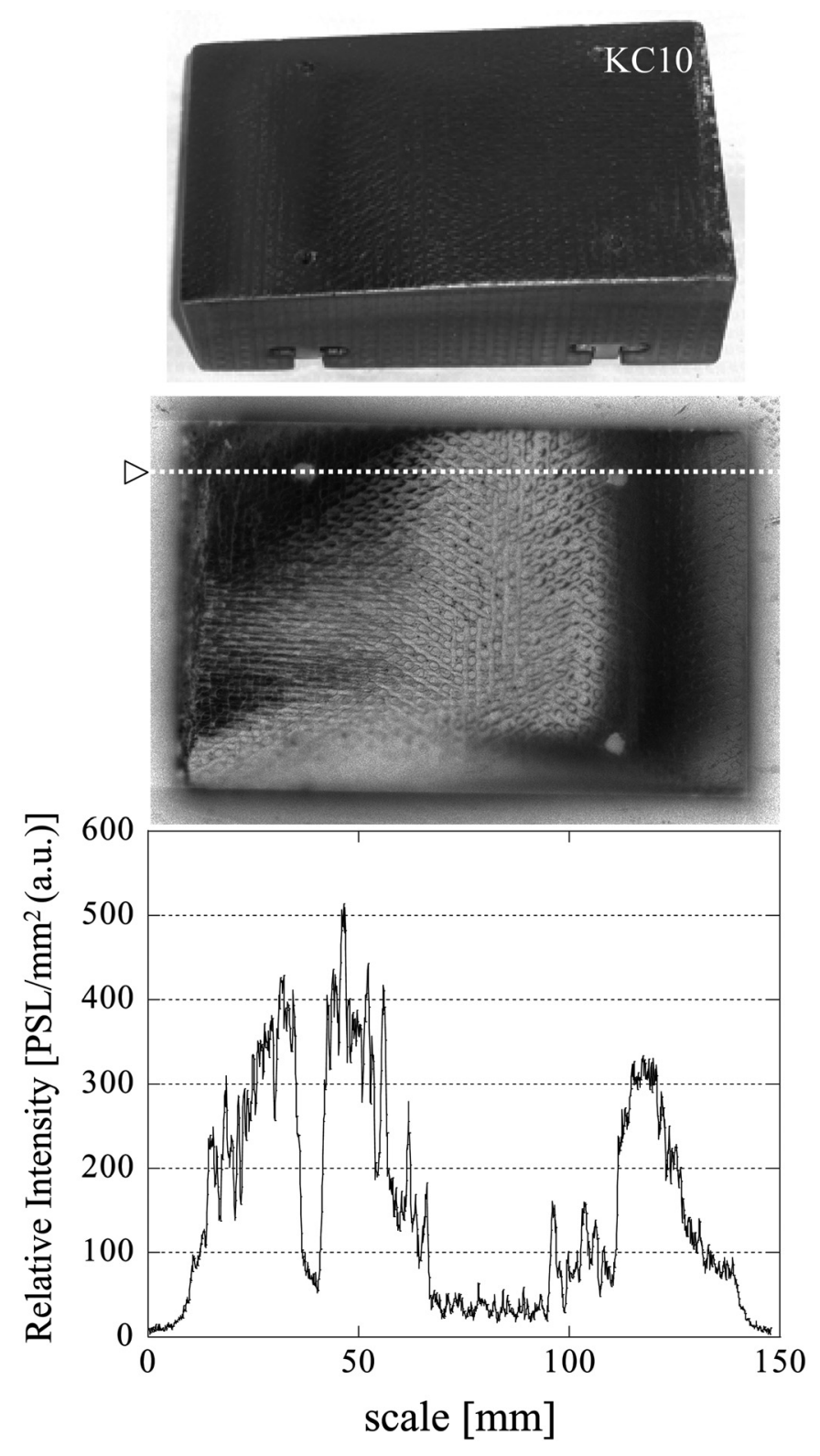

Fig. 3. Results for tile KC10 located at middle region of the bumper limiter. The center of the surface was the erosion area, while the redeposited layer lay near the erosion region.

TFTR limiter [13].) The imaging plates were also exposed when covered with two films of 2 micron and 12 micron thickness, i.e., sufficient film thickness to completely absorb tritium beta particles. Permeation of tritium gas through the 12 micron film was ruled out by measurements with a surface activity monitor sensitive only to tritium betas [14]. The IP exposure pattern showed attenuation by the graphite tile inconsistent with exposure by more penetrating gamma radiation from metallic impurities. The remaining possibilities are exposure due to bremstrahlung generated by tritium betas, or by high-energy betas from ${ }^{60} \mathrm{Co}$. This will be subject of a future investigation.

\section{Discussion}

In TFTR, the deposition pattern on the bumper limiter is dependent on the plasma parameters, and the angle of incidence of the magnetic field lines on the tile surfaces [15]. In particular, as shown in Fig. 2, the tritium image was
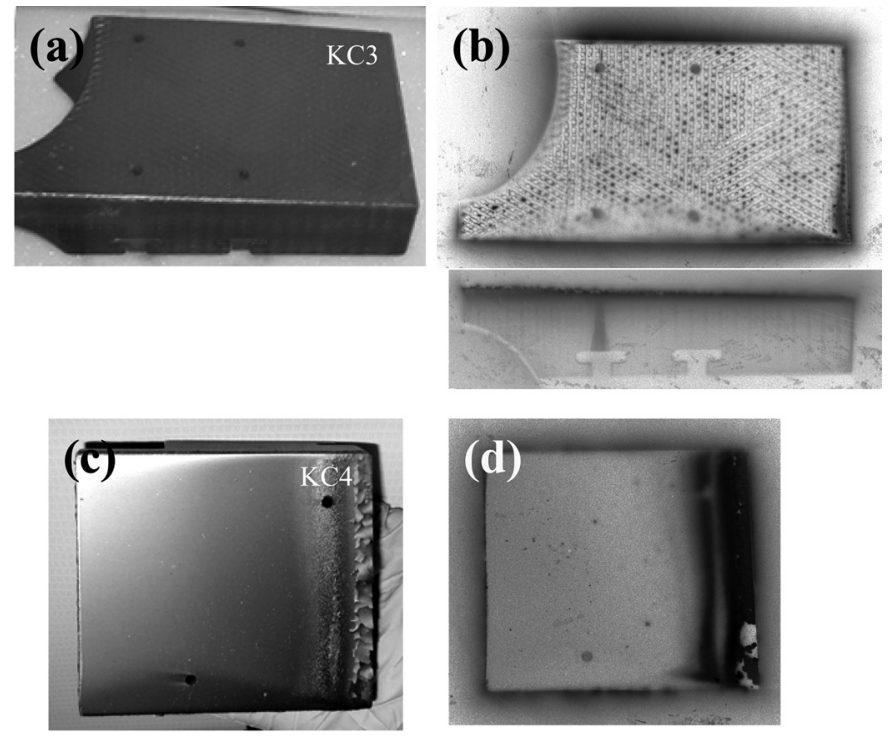

Fig. 4. (a) Photograph and (b) tritium image of KC3 (gray scale), plasma facing and side views. (c) Photograph of KC4 and (d) its tritium image (gray scale).
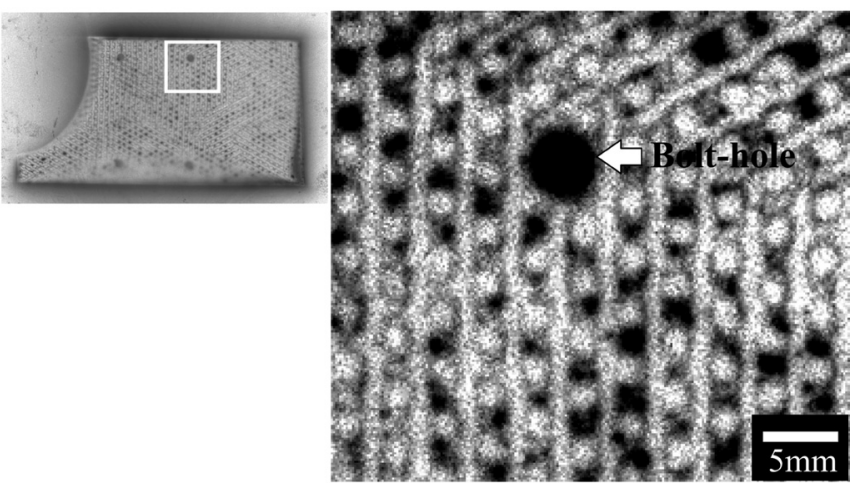

Fig. 5. Enlarged tritium image of KC3 (CFC). The area enclosed by white square is magnified. Tritium retention is higher in the matrix in between the fibers.

very closely correlated with carbon deposition. Hence, we focus on the relation of tritium distribution and erosion/ deposition phenomena.

In-vessel observation showed that part of deposition layers were easily peeled off and became flakes after the vacuum vessel was opened [16,17] (Fig. 2). In both cases of KA7 and KA2 (not shown), for example, the deposited layer of which the PSL intensity reaches around 350-400 [PSL $/ \mathrm{mm}^{2}$ (Arb.Unit.)] tended to become flakes. In addition, even for the CFC tiles, it was found that the depositions whose PSL intensities were more than $350 \mathrm{PSL} / \mathrm{mm}^{2}$ also became flakes. Actually, a separate quantitative analysis showed that the exfoliated flakes retained about $3 \mathrm{Ci}$ per $1 \mathrm{~g}$ flake $(\mathrm{T} / \mathrm{C} \sim 0.01)$ [15]. The IP images gave not only detailed tritium distribution, but also important information of transport of carbon and other impurities. In particular, the tritium image of the CFC tiles suggests local erosion and transport of $\mathrm{C}$. A CFC tile such as $\mathrm{KC} 3$ was constructed using AMOCO P-25 fiber and densified using a coal tar pitch. The woven preform was pressure impregnated with a liquid pitch to fill the voids between the yarn, densified at high pressure (up to $\sim 10^{4} \mathrm{~N} / \mathrm{cm}^{2}$ ), and heat treated at about $2700 \mathrm{~K}$ to produce a rigid multi-dimensional reinforced graphite structure [18]. 
Through this process, the gap between the fibers was filled up by pyrolytic or amorphous like carbon to become a matrix. Accordingly, there are two possible scenarios for the appearance of local inhomogeneities in Fig. 5. (1) The matrix areas contain voids [19] that can trap codeposited tritium more effectively than the fiber bundles. (2) Since the crystal perfection of such matrix carbon is generally poorer than that of the carbon fiber (in other words, carbon matrix is softer than fiber), the matrix areas are very likely to be eroded preferentially, resulting in dug area.

Most of the eroded carbon atoms were promptly redeposited near the erosion point together with hydrogen isotopes [20]. In previous studies, transport of carbon and other impurities in TFTR boundary plasma have been modeled [21,22], and BBQ code [3] showed that the erosion products have a range of several $\mathrm{cm}$ before redeposition. The depositions could be re-eroded unless they stuck where the erosion yield was low. This repetition of erosion and deposition in the short-range led to middle- or long-range transport. (Here, "middle-" is from several cm to several $10 \mathrm{~cm}$, and 'long-' is no limitation.) As a consequence of such multiple erosion and deposition, tritium image of $\mathrm{KC} 3$ and $\mathrm{KC} 4$ showed a clearly woven structure in the totally eroded area.

In case of the graphite tile $(\mathrm{KC} 4)$ neighboring to $\mathrm{KC} 3$, owing to its homogeneous structure, no preferential sputtering appeared resulting in uniform erosion and tritium retention as shown in Fig. 4(c) and (d), respectively.

Surprisingly high tritium retention in all sides of tiles located at the eroded area could also be attributed to multistep carbon transport. On the tile edge, in other words in gaps between the tiles, plasma cannot penetrate and, hence, no erosion occurred as evident by the codeposition of radioactive metallic impurities. Accordingly, the tritium concentration in the side-surfaces of tiles from the erosiondominant region was much higher than that from other regions of the bumper limiter.

\section{Conclusion}

Tritium surface distribution of TFTR bumper limiter tiles was successfully measured by TIPT. The tritium image obtained by IP showed detailed tritium distribution reflecting erosion-codeposition pattern on the bumper limiter.

Erosion products were redeposited with hydrogen isotopes after transport along the magnetic field lines. The IP images clearly showed that:

1. On the plasma-facing surface of tiles from the erosiondominant region of the bumper limiter, codepositions were found at the matrix area of CFC tiles. Eroded materials were promptly redeposited on the carbon matrix area. Deposition could occur in cavities in the matrix independent of the distance traveled from the erosion location.

2. Promptly redeposited materials interact with plasma flux and are sputtered again. Repetition of several cycles of erosion/redeposition results in middle-range $(\sim$ several $10 \mathrm{~cm})$ or long-range carbon transport. This explains significantly high PSL intensities found at four side-surfaces of the erosion-dominant tiles.

Some of the codeposits on the isotopic graphite tiles located at the deposition dominated area became detached after exposure to air. Activated metals were also codeposited with tritium, as already observed.

All above results indicate that tritium profiling could be an additional diagnostics for plasma wall interactions, particularly for the investigation of erosion and deposition phenomena.

\section{Acknowledgments}

The authors would like to acknowledge the invaluable assistance of S. Languish, A. Planetta of the tritium group of PPPL, as well as the assistance of Dr. Carlos A. Avila-Orta of BNL for the IP reading. The great support regarding TIPT by Dr. T. Saze and Professor K. Nishizawa of Radioisotope Center, Nagoya University, is also appreciated. This work was partly supported by a Grant-in-Aid of the Ministry of Education, Culture, Sports, Science and Technology, Japan and by United States Department of Energy under Contract DE-AC02-76CH03073.

\section{References}

1. Andrew, P. et al., J. Nucl. Mater. 266-269, 153 (1999).

2. Skinner, C. H. et al., J. Nucl. Mater. 241-243, 214 (1997).

3. Skinner, C. H. et al., J. Nucl. Mater. 290-293, 486 (2001).

4. Miyasaka, K. et al., J. Nucl. Mater. 290-293, 448 (2001).

5. Tanabe, T. et al., Fusion Sci. Technol. 41, 877 (2002).

6. Sugiyama, K. et al., Physica Scripta T103, 56 (2003).

7. Sugiyama, K. et al., J. Nucl. Mater. 313-316, 507 (2003).

8. Skinner, C. H., Gentile, C. A., Ciebiera, L. and Langish, S., Fus. Sci Technol, in press (2003).

9. Skinner, C. H., Gentile, C. A, Menon, M. M. and Barry, R. E., Nucl. Fus. 39, 1081 (1999).

10. McSmith, M. D., Loesser, G. D., Owens, D. K., Fusion Technology 26, 498 (1994).

11. Hsu, W. L. et al., J. Vac. Sci. Technol. A7, 1065 (1989).

12. Mills, B. E. et al., J. Nucl. Mater. 162-164, 343 (1989).

13. Wampler, W. R. et al., J. Vac. Sci. Technol. A6, 2111 (1998).

14. Kherani, N. P. and Shmayda, W. T., Fus. Technol. 28, 893 (1995).

15. Skinner, C. H. et al., J. Nucl. Mater. 266-269, 940 (1999).

16. Skinner, C. H. et al., Princeton Plasma Phys. Lab. publication reports. PPPL-3379 (2000).

17. Skinner, C. H. et al., Nucl. Fus. 39, 1081 (1999).

18. Fiber Materials Inc. Material description. FMI. Website: http:// www.fibermaterialsinc.com.

19. Skinner, C. H. et al., Physica Scripta T103, 34 (2003).

20. Ohya, K. and Kawakami. R., Jpn., J. Appl. Phys. 40, 5424 1995).

21. Hua, T. Q. et al., J. Nucl. Mater. 196-198, 514 (1992).

22. Brooks, J. N. et al., J. Nucl. Mater. 162-164, 363 (1989). 


\section{External Distribution}

Plasma Research Laboratory, Australian National University, Australia

Professor I.R. Jones, Flinders University, Australia

Professor João Canalle, Instituto de Fisica DEQ/IF - UERJ, Brazil

Mr. Gerson O. Ludwig, Instituto Nacional de Pesquisas, Brazil

Dr. P.H. Sakanaka, Instituto Fisica, Brazil

The Librarian, Culham Laboratory, England

Mrs. S.A. Hutchinson, JET Library, England

Professor M.N. Bussac, Ecole Polytechnique, France

Librarian, Max-Planck-Institut für Plasmaphysik, Germany

Jolan Moldvai, Reports Library, Hungarian Academy of Sciences, Central Research Institute for Physics, Hungary

Dr. P. Kaw, Institute for Plasma Research, India

Ms. P.J. Pathak, Librarian, Institute for Plasma Research, India

Ms. Clelia De Palo, Associazione EURATOM-ENEA, Italy

Dr. G. Grosso, Instituto di Fisica del Plasma, Italy

Librarian, Naka Fusion Research Establishment, JAERI, Japan

Library, Laboratory for Complex Energy Processes, Institute for Advanced Study, Kyoto University, Japan

Research Information Center, National Institute for Fusion Science, Japan

Dr. O. Mitarai, Kyushu Tokai University, Japan

Dr. Jiangang Li, Institute of Plasma Physics, Chinese Academy of Sciences, People's Republic of China

Professor Yuping Huo, School of Physical Science and Technology, People's Republic of China

Library, Academia Sinica, Institute of Plasma Physics, People's Republic of China

Librarian, Institute of Physics, Chinese Academy of Sciences, People's Republic of China

Dr. S. Mirnov, TRINITI, Troitsk, Russian Federation, Russia

Dr. V.S. Strelkov, Kurchatov Institute, Russian Federation, Russia

Professor Peter Lukac, Katedra Fyziky Plazmy MFF UK, Mlynska dolina F-2, Komenskeho Univerzita, SK-842 15 Bratislava, Slovakia

Dr. G.S. Lee, Korea Basic Science Institute, South Korea

Institute for Plasma Research, University of Maryland, USA

Librarian, Fusion Energy Division, Oak Ridge National Laboratory, USA

Librarian, Institute of Fusion Studies, University of Texas, USA

Librarian, Magnetic Fusion Program, Lawrence Livermore National Laboratory, USA

Library, General Atomics, USA

Plasma Physics Group, Fusion Energy Research Program, University of California at San Diego, USA

Plasma Physics Library, Columbia University, USA

Alkesh Punjabi, Center for Fusion Research and Training, Hampton University, USA

Dr. W.M. Stacey, Fusion Research Center, Georgia Institute of Technology, USA

Dr. John Willis, U.S. Department of Energy, Office of Fusion Energy Sciences, USA

Mr. Paul H. Wright, Indianapolis, Indiana, USA 
The Princeton Plasma Physics Laboratory is operated by Princeton University under contract with the U.S. Department of Energy.

\author{
Information Services \\ Princeton Plasma Physics Laboratory \\ P.O. Box 451 \\ Princeton, NJ 08543
}

Phone: 609-243-2750

Fax: 609-243-2751

e-mail: pppl_info@pppl.gov

Internet Address: http://www.pppl.gov 